\title{
Transplantation of initially rejected donor lungs after ex vivo lung perfusion
}

\author{
Andreas Wallinder, MD, ${ }^{\mathrm{a}}$ Sven-Erik Ricksten, MD, PhD, ${ }^{\mathrm{b}}$ Christoffer Hansson, MSc, ${ }^{\mathrm{b}}$ Gerdt C. Riise, MD, \\ $\mathrm{PhD},{ }^{\mathrm{c}}$ Martin Silverborn, MD, PhD, ${ }^{\mathrm{a}}$ Hans Liden, $\mathrm{MD}, \mathrm{PhD},{ }^{\mathrm{a}}$ Michael Olausson, $\mathrm{MD}, \mathrm{PhD},{ }^{\mathrm{c}}$ and \\ Göran Dellgren, $\mathrm{MD}, \mathrm{PhD}^{\mathrm{a}, \mathrm{c}, \mathrm{d}}$
}

Objective: Ex vivo lung perfusion has the potential to increase the number of patients treated with lung transplantation. Our initial clinical experience with ex vivo lung perfusion is reviewed as well as early clinical outcome in patients transplanted with reconditioned lungs.

\begin{abstract}
Methods: Six pairs of donor lungs deemed unsuitable for transplantation underwent ex vivo lung perfusion with Steen solution mixed with red blood cells to a hematocrit of $10 \%$ to $15 \%$. After reconditioning, lung function was evaluated and acceptable lungs were transplanted. Technical experience with ex vivo lung perfusion as well as clinical outcome for patients transplanted with ex vivo lung perfusion-treated lungs were evaluated.
\end{abstract}

\begin{abstract}
Results: Donor lungs initially rejected either as a result of an inferior partial pressure of arterial oxygen/ fraction of inspired oxygen ( $\mathrm{n}=5$; mean, $20.5 \mathrm{kPa}$; range, 9.1-29.9 kPa) or infiltrate on chest radiograph $(\mathrm{n}=1) \mathrm{im}$ proved their oxygenation capacity to a mean partial pressure of arterial oxygen/fraction of inspired oxygen of $57 \pm 10 \mathrm{kPa}$ during the ex vivo lung perfusion (mean improvement, $33.6 \mathrm{kPa}$; range, $21-51 \mathrm{kPa} ; P<.01$ ). During evaluation, hemodynamic (flow, vascular resistance, pressure) and respiratory (peak airway pressure, compliance) parameters were stable. Two single lungs were not used for lung transplantation because of subpleural hematoma or edema. Six recipients from the regular waiting list underwent single $(n=2)$ or double $(n=4)$ lung transplantation. One patient had primary graft dysfunction grade 2 at 72 hours. Median time to extubation was 7 hours. All patients survived 30 days and were discharged in good condition from the hospital.
\end{abstract}

Conclusions: The use of ex vivo lung perfusion seems safe and indicates that some lungs otherwise refused for lung transplantation can be recovered and transplanted with acceptable short-term results. (J Thorac Cardiovasc Surg 2012;144:1222-8)

Lung transplantation (LTx) is the treatment of choice for end-stage lung disease, but the shortage of donor lungs remains the limiting factor. Recent national data from the United States reports use of $22 \%$ of lungs from multiorgan donors; corresponding U.K. data indicate $17 \%{ }^{1,2}$ After improvements in donor management and implementation of extended donor criteria, lungs from as many as $30 \%$ to $40 \%$ of multiorgan donors in Sweden have been transplanted during the past few years.

From the Departments of Cardiothoracic Surgery, ${ }^{\text {a }}$ Cardiothoracic Anesthesia and Intensive Care, ${ }^{\mathrm{b}}$ Transplant Institute, ${ }^{\mathrm{c}}$ Sahlgrenska University Hospital, Gothenburg, Sweden; and the Department of Molecular and Clinical Medicine, ${ }^{\mathrm{d}}$ Institute of Medicine, Sahlgrenska Academy, University of Gothenburg, Gothenburg, Sweden. This work was supported by grants from the Swedish Heart and Lung Foundation, the Jan Elgqvist Foundation, and an ALF/LUA research grant from Sahlgrenska University Hospital.

Disclosure: Authors have nothing to disclose with regard to commercial support.

Read at the 38th Annual Meeting of The Western Thoracic Surgical Association, Maui, Hawaii, June 27-30, 2012.

Received for publication May 21, 2012; revisions received July 15, 2012; accepted for publication Aug 1, 2012; available ahead of print Sept 19, 2012

Address for reprints: Göran Dellgren, MD, PhD, Transplant Institute and Department of Cardiothoracic Surgery, Sahlgrenska University Hospital, University of Gothenburg, SE- 413 45, Gothenburg, Sweden (E-mail: goran.dellgren@vgregion.se).

$0022-5223 / \$ 36.00$

Copyright (c) 2012 by The American Association for Thoracic Surgery

http://dx.doi.org/10.1016/j.jtcvs.2012.08.011
Reconditioning and evaluation of lungs initially rejected for transplantation with ex vivo lung perfusion (EVLP) has been used to differentiate reversible from irreversible pathology. ${ }^{3-5}$ In 2007, Steen and colleagues ${ }^{6}$ reported the first transplantation of an ex vivo reconditioned lung. Thereafter, transplantations of initially rejected but EVLP reconditioned lungs from brain dead donors have been reported in 32 patients from 4 centers. ${ }^{4,5,7,8}$ We present our early clinical experience with EVLP management of initially rejected donor lungs with subsequent LTx.

\section{MATERIALS AND METHODS Patients}

The Ethics committee of the University of Gothenburg approved this study. All recipients on the LTx waiting list were eligible for transplantation with lungs reconditioned with EVLP. Recipients were matched for compatible blood group, size, and urgency, and were brought to the transplantation center during the organ retrieval procedure. Recipient characteristics are presented in Table 1.

\section{Donor Selection and Characteristics}

Between January 2011 and October 2011, lungs from 107 brain dead donors were offered to our center; 27 were accepted for transplantation and 80 were rejected because of no matching recipient $(26 \%)$; advanced smoking history $(18 \%)$; high donor age (14\%); inferior blood gases despite efforts such as recruitment maneuvers, bronchial suction, and diuretic 


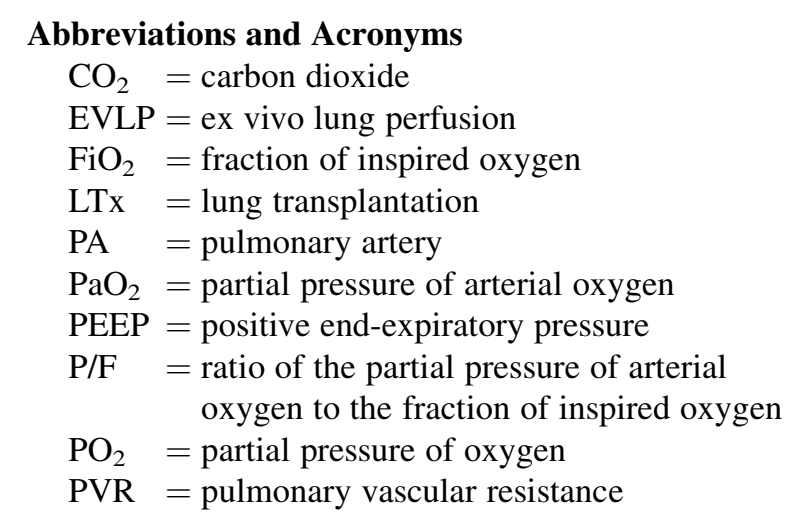

treatment $(8 \%)$; aspiration of gastric content $(8 \%)$; and other signs of inferior lung function, trauma, macroscopic abnormalities, or unclear reasons $(19 \%)$. Six pairs of the rejected donor lungs were subjected to EVLP. Criteria for EVLP evaluation were (1) best ratio of the partial pressure of arterial oxygen to the fraction of inspired oxygen $(\mathrm{P} / \mathrm{F})$ in the intensive care unit $<40 \mathrm{kPa}$; and/or (2) radiologic signs of extensive lung edema; and/or (3) radiologic signs of infiltrates suggestive of pneumonia, lung infarction, or aspiration.

The lungs were harvested in a standard fashion with antegrade Perfadex (Vitrolife AB, Gothenburg, Sweden) flush, cold storage in Perfadex and were kept on ice during transport. If the heart was harvested, an additional piece of the ascending aorta was brought for elongation of the pulmonary artery (PA) to facilitate connection of the lung to the EVLP artery cannula. For detailed donor characteristics see Table 2.

\section{Ex Vivo Lung Perfusion}

EVLP was performed with the CE-marked Vivoline LS1 (Vivoline Medical AB, Lund, Sweden) (Figures 1 and 2). The system was primed with $2.0 \mathrm{~L}$ of Steen Solution (Vitrolife AB) mixed to a hematocrit level of $10 \%$ to $15 \%$ with bank blood, compatible and cross-checked to the selected recipient. Meropenem $100 \mathrm{mg}$ (AstraZeneca AB, Sodertalje, Sweden) and 10000E Heparin (LEO Pharmaceutical, Copenhagen, Denmark) were added to the perfusate. Before the lungs were connected to the EVLP unit, the $\mathrm{pH}$ in the solution was corrected to between 7.35 and 7.45 with isotonic trometamol (Addex-THAM, Fresenius Kabi AB, Uppsala, Sweden).

To perform a safe cannulation of the PA, a 3- to 4-cm graft of the ascending aorta from the donor was used to elongate the PA in 3 cases. The trachea was connected to the mechanical ventilator via a silicon tube size matched for the tracheal diameter. The remnant of the left atrium was opened widely to prevent pulmonary vein outflow obstruction and to keep left atrial pressure near $0 \mathrm{~mm} \mathrm{Hg}$. A temperature probe was sutured inside the left atrium. All perfusion was performed in an antegrade fashion. Figure 1 illustrates the setup of the lung in the EVLP system.

The different EVLP phases (Figure 3) were as follows:

Reconditioning phase. Initially, the lungs were perfused at a flow rate of $0.5 \mathrm{~L} / \mathrm{min}$. The shunt from the inflow cannula was closed when the perfusate was de-aired. The lungs were warmed to a target of $36^{\circ} \mathrm{C}$, and the temperature difference between lung blood inflow and outflow was not allowed to exceed $8^{\circ} \mathrm{C}$. The flow rate was increased gradually to a target level of $70 \mathrm{~mL} / \mathrm{min}$ per kilogram donor weight, during which the PA pressure was measured continuously and limited to $15 \mathrm{~mm} \mathrm{Hg}$. If initial perfusion was uneventful, the PA pressure limit was increased to $20 \mathrm{~mm}$ $\mathrm{Hg}$. When the temperature reached $32^{\circ} \mathrm{C}$, mechanical volume-controlled ventilation was started at an initial minute-volume of 1.5 times the PA flow, a positive end-expiratory pressure (PEEP) level of $5 \mathrm{~cm} \mathrm{H}_{2} \mathrm{O}$, a rate of 12 breaths/min, and an $\mathrm{FiO}_{2}$ of 0.5 . If uneventful, ventilation was increased gradually to a maximum of $100 \mathrm{~mL} / \mathrm{min}$ per kilogram donor weight. At $36^{\circ} \mathrm{C}$, an incremental PEEP trial was performed to recruit atelectatic lobes/segments. Blood samples for gas analysis were drawn from the left atrium and, if deemed acceptable, EVLP was shifted to the evaluation phase. If blood gases were suboptimal, further treatment was performed in the reconditioning phase.

Evaluation phase. The oxygenator was now used to deoxygenate the perfusate and to add carbon dioxide $\left(\mathrm{CO}_{2}\right)$. Ten minutes after the start of the evaluation phase, samples for blood gas analysis were drawn from the left atrium and from the circuit after the oxygenator in the EVLP system (the latter to make sure that the perfusate was deoxygenated adequately). $\mathrm{FiO}_{2}$ was then decreased to 0.21 and, after another 10 -minute period, new blood samples were drawn. $\mathrm{FiO}_{2}$ was finally set to 1.0 followed by a third set of blood gas analyses. A collapse test was performed at $\mathrm{FiO}_{2} 1.0$ by disconnecting the tracheal tube at the end of inspiration. Recoil of the lungs was evaluated subjectively. Pulmonary mechanics as well as end-tidal $\mathrm{CO}_{2}$ concentrations were monitored continuously (Datex-Ohmeda Anesthesia Monitor; GE Health Care, Chalfont St. Giles, UK). Physiologic dead space was calculated as $\left(\mathrm{PaCO}_{2}-\right.$ End-tidal $\left.\mathrm{CO}_{2}\right) / \mathrm{PaCO}_{2}$. Static lung compliance was defined as Tidal volume/(Inspiratory plateau pressure - PEEP). Left atrial pressure was assumed to be $0 \mathrm{~mm} \mathrm{Hg}$, and pulmonary vascular resistance (PVR) was consequently defined as Mean PA pressure/PA flow $\times 80$.

Acceptance of EVLP-evaluated lungs for transplanta-

tion. The decision to transplant the lungs was based on (1) a lung oxygenation capacity with a $\mathrm{P} / \mathrm{F}$ ratio of $>40 \mathrm{kPa}$ during the evaluation phase, (2) stable hemodynamic and respiratory variables (PVR, peak airway pressures, and lung compliance) during EVLP, (3) absence of macroscopic signs of pneumonic infiltrates or lung infarctions, and (4) a normal collapse test.

After the evaluation test, the lungs were cooled in the EVLP system (core cooling) to $12^{\circ} \mathrm{C}$. The ventilator was disconnected at $32^{\circ} \mathrm{C}$ and the trachea was clamped when $50 \%$ of the tidal volume was exhaled. In the first 2 pair of lungs, the PA was clamped after an antegrade flush of $1 \mathrm{~L}$ Perfadex with additives at $12^{\circ} \mathrm{C}$, and thereafter stored in Perfadex on ice. The subsequent donor lungs $(n=4)$ had surface cooling instituted with the EVLP perfusate continuously flowing over the compress-imbedded lungs. Temperature of the donor lungs during surface cooling were kept at $8^{\circ} \mathrm{C}$. In case of double LTx, the second lung was kept cold by continuous surface cooling as the first lung was transplanted.

\section{Lung Transplantation}

When possible, surgery was performed as bilateral sequential thoracotomies without extracorporeal circulation. Postoperatively, the patients who underwent LTx received treatment according to our standard protocol for LTx. Lung spirometry was performed at the time of discharge from the hospital.

\section{Statistical Analysis}

Data were collected prospectively. Continuous data are presented as mean and range. Categorical data are presented as frequency and percentage. Early mortality was defined as hospital mortality, which is all-cause death within any time interval after the LTx. Differences between values before and after treatment were calculated with the Wilcoxon signedrank test. A $P$ value of $<.05$ was considered as statistically significant.

\section{RESULTS}

Six pair of lungs were evaluated with EVLP. The evaluated lungs were initially rejected for LTx as a result of inferior blood gases in the intensive care unit $(n=5)$ or advanced bilateral infiltrates on chest radiograph $(\mathrm{n}=1)$. 
TABLE 1. Recipient characteristics

\begin{tabular}{|c|c|c|c|c|c|c|c|}
\hline \multirow[b]{2}{*}{ Variable } & \multicolumn{7}{|c|}{ Recipient } \\
\hline & 1 & 2 & 3 & 4 & 5 & 6 & Mean \\
\hline Age, $y$ & 56 & 55 & 29 & 17 & 51 & 69 & 46 \\
\hline Height, $\mathrm{cm}$ & 160 & 170 & 171 & 151 & 178 & 168 & 166 \\
\hline Weight, kg & 55 & 61 & 52 & 41 & 84 & 78 & 62 \\
\hline Blood group & A & A & A & A & B & B & \\
\hline Diagnosis & COPD & COPD & $\mathrm{CF}$ & KS & COPD & Fibrosis & \\
\hline $\begin{array}{c}\mathrm{FVC}, \mathrm{L} / \% \text { of } \\
\text { predicted }\end{array}$ & $1.7 / 62$ & $1.9 / 59$ & $2.0 / 43$ & $2.0 / 58$ & $2.7 / 59$ & $1.4 / 51$ & 1.95 \\
\hline $\begin{array}{r}\text { FEV } 1.0, \mathrm{~L} / \% \\
\text { of predicted }\end{array}$ & $0.5 / 22$ & $0.5 / 26$ & $1.1 / 31$ & $1.0 / 32$ & $0.8 / 22$ & $1.2 / 52$ & 0.85 \\
\hline
\end{tabular}

Rejections were based on the best recorded blood gas after optimization of lung function. After EVLP, 2 single lungs were still deemed unsuitable as a result of consolidation or edema and were not used for LTx. Donor characteristics are described in Table 2.

\section{EVLP Outcome}

In EVLP no. 1, the lungs were rejected at a $\mathrm{P} / \mathrm{F}$ ratio of $16.7 \mathrm{kPa}$. Chest radiography showed basal infiltrates. After $134 \mathrm{~min}$ of EVLP, the P/F ratio improved to $67.4 \mathrm{kPa}$. A PA flow of $77 \%$ of the estimated was reached a $\mathrm{PA}$ pressure of $20 \mathrm{~mm} \mathrm{Hg}$. PVR was stable around $580 \mathrm{dynes} \cdot \mathrm{sec} \cdot \mathrm{cm}^{-5}$. Double LTx was performed and the recipient had an uneventful recovery.

In EVLP no. 2, the lungs were rejected at a $\mathrm{P} / \mathrm{F}$ ratio of $17.0 \mathrm{kPa}$. Chest radiography showed edema. After $220 \mathrm{~min}$ of EVLP, the P/F ratio improved to $40.6 \mathrm{kPa}$. A PA flow of $55 \%$ of the estimated was reached at a PA pressure of 20 $\mathrm{mm} \mathrm{Hg.} \mathrm{PVR} \mathrm{was} \mathrm{reasonably} \mathrm{stable} \mathrm{around} 650$ dynes . $\mathrm{sec} \cdot \mathrm{cm}^{-5}$. The lung weight decreased from $2550 \mathrm{~g}$ to $1950 \mathrm{~g}$. The intended double LTx was converted to single LTx because of complicated recipient lung adhesions. It was also assumed that transplantation of the second lung would result in the need for extra corporeal circulation during or after the procedure because of severely impaired blood gases after transplantation of the first lung. The decision to not transplant the second lung was supported by the fact that the patient was planned for either single or double LTx. Indeed, the transplanted lung showed immediate signs of dysfunction in terms of extensive lung edema. The recipient had primary graft dysfunction grade 2 at 36 hours and was dependent on mechanical ventilation for 24 days.

In EVLP no. 3, the lungs were rejected at a $\mathrm{P} / \mathrm{F}$ ratio of $29.8 \mathrm{kPa}$. Chest radiography showed localized infiltrate and edema. After $116 \mathrm{~min}$ of EVLP, the P/F ratio improved to $56.8 \mathrm{kPa}$. PA flow was not restricted by the PA pressure limit. PVR was stable around 300 dynes $\cdot \mathrm{sec} \cdot \mathrm{cm}^{-5}$. Double LTx was performed and the recipient had an uneventful recovery.

In EVLP no. 4, the lungs were rejected at a P/F ratio of $41.8 \mathrm{kPa}$. Chest radiography showed extensive bilateral infiltrates. After $93 \mathrm{~min}$ of EVLP, the P/F ratio improved to $70.2 \mathrm{kPa}$. PA flow was not restricted by the PA pressure limit. PVR was stable around 370 dynes $\cdot \mathrm{sec} \cdot \mathrm{cm}^{-5}$. Double LTx was performed and the recipient had an uneventful recovery.

In EVLP no. 5, the lungs were rejected at a $\mathrm{P} / \mathrm{F}$ ratio of $29.9 \mathrm{kPa}$. Chest radiography showed bilateral basal infiltrates. After $112 \mathrm{~min}$ of EVLP, the P/F ratio improved to $49.9 \mathrm{kPa}$. PA flow was not restricted by the PA pressure limit. PVR was stable around $245 \mathrm{dynes} \cdot \mathrm{sec} \cdot \mathrm{cm}^{-5}$. Double LTx was performed and the recipient had an uneventful recovery.

In EVLP no. 6, the lungs were rejected at a P/F ratio of $9.1 \mathrm{kPa}$. Chest radiography showed extensive infiltrate on the right side. After $295 \mathrm{~min}$ of EVLP, the P/F ratio improved to $59.6 \mathrm{kPa}$ in the left lung and remained at 13.6 in the right lung, which was severely consolidated. PA flow was not restricted by the PA pressure limit. PVR was stable around 320 dynes $\cdot \mathrm{sec} \cdot \mathrm{cm}^{-5}$. The lung weight decreased from $1650 \mathrm{~g}$ to $1250 \mathrm{~g}$. Single LTx was performed and the recipient had an uneventful recovery.

TABLE 2. Donor characteristics

\begin{tabular}{|c|c|c|c|c|c|c|c|}
\hline \multirow[b]{2}{*}{ Variable } & \multicolumn{7}{|c|}{ Donor no. } \\
\hline & 1 & 2 & 3 & 4 & 5 & 6 & Mean \\
\hline Age, y & 22 & 52 & 42 & 52 & 59 & 19 & 41 \\
\hline Height, $\mathrm{cm}$ & 170 & 168 & 172 & 145 & 180 & 175 & 168 \\
\hline Weight, kg & 80 & 66 & 62 & 61 & 102 & 55 & 71 \\
\hline Blood group & A & A & A & A & B & $\mathrm{B}$ & \\
\hline Cause of death & SAH & SAH & SAH & SAH & SDH & IBI & \\
\hline $\begin{array}{l}\mathrm{P} / \mathrm{F} \text { ratio (in donor } \\
\text { when accepted for EVLP) }\end{array}$ & 16.7 & 17 & 29.8 & 41.8 & 29.9 & 9.1 & 24.1 \\
\hline Radiographic findings & Bilateral basal infiltrate & Edema & Infiltrate, edema & Bilateral infiltrate & Bilateral basal infiltrate & Extensive infiltrate & \\
\hline $\begin{array}{l}\text { Transport, min; cold flush to } \\
\text { start EVLP }\end{array}$ & 143 & 217 & 216 & 191 & 221 & 336 & 220 \\
\hline
\end{tabular}




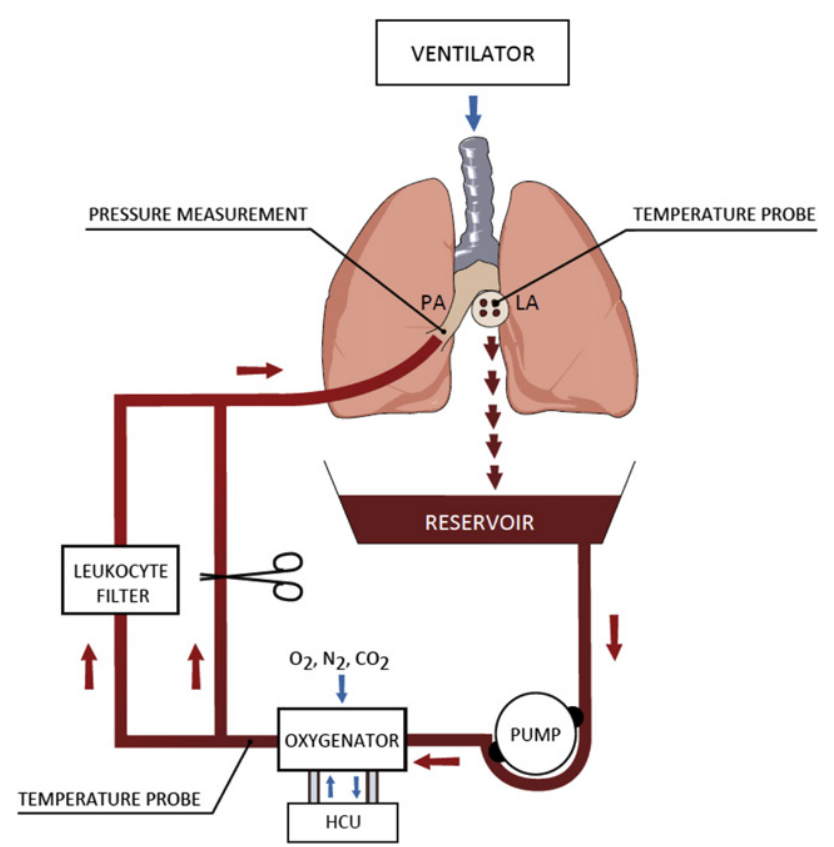

FIGURE 1. Schematic drawing of the ex vivo lung perfusion unit. The blood enters the open reservoir via the remnant of the left atrium. Samples for blood gas analyses are drawn from the left atrium $(L A)$ and from a port after the oxygenator where drugs can also be administered. $P A$, Pulmonary artery; $H C U$, Heater-cooler unit.

Detailed data from EVLP are presented in Tables 3 through 5. Mean duration of EVLP was $231 \mathrm{~min}$. The mean reconditioning time was $104 \mathrm{~min}$ before initiation of the evaluation phase. Two pairs of lungs (nos. 2 and 6 ) were heavy with edema and reconditioned for 162 and 242 minutes, respectively. These 2 pairs of lungs had the lowest $\mathrm{P} / \mathrm{F}$ ratios and the lowest lung compliance (both 53 $\mathrm{mL} / \mathrm{cm} \mathrm{H}_{2} \mathrm{O}$ ).

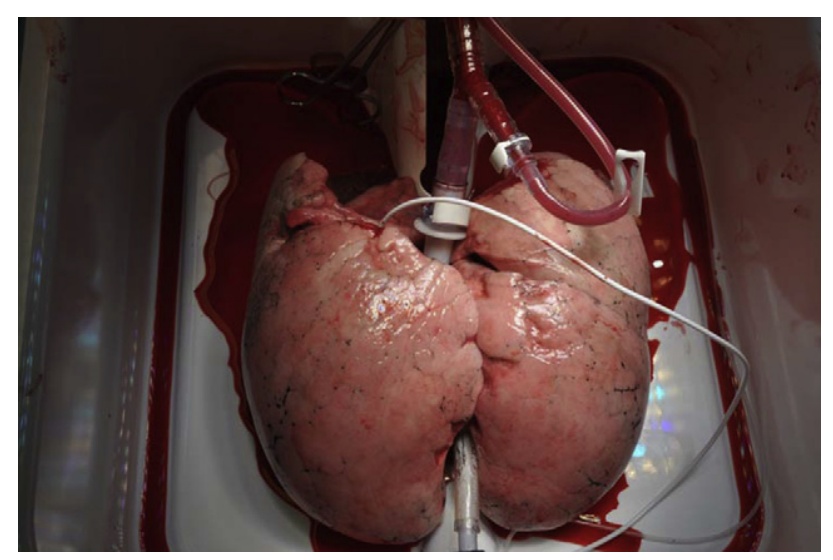

FIGURE 2. Picture of a setup of the lung in the Vivoline ex vivo lung perfusion circuit. Cannula to pulmonary artery in top. Cannula to trachea in bottom. Shunt closed with plastic clamp in upper right corner. White temperature probe crossing the lung.
During EVLP, the P/F ratio improved, with a mean of $33.6 \mathrm{kPa}$ (range, 21.0-50.7 kPa) compared with the donor $\mathrm{P} / \mathrm{F}$ ratio (range, 9.1-41.8 $\mathrm{KPa}$ ).

Mean peak airway pressure was $15.3 \mathrm{~cm} \mathrm{H}_{2} \mathrm{O}$ at $\mathrm{FiO}_{2} 1.0$ and did not exceed $18 \mathrm{~cm} \mathrm{H}_{2} \mathrm{O}$ in any pair of lungs. Mean static lung compliance at the end of EVLP was $59 \mathrm{~mL} / \mathrm{cm}$ $\mathrm{H}_{2} \mathrm{O}$ (range, $53-65 \mathrm{~mL} / \mathrm{cm} \mathrm{H}_{2} \mathrm{O}$ ). Mean dead space fraction was $35 \%$ (range, $17-45 \%$ ). In 2 pairs of lungs (nos. 1 and 2), PA flow was limited (77\% and 50\% of target, respectively) by the preset upper PA pressure limit of $20 \mathrm{~mm}$ $\mathrm{Hg}$. These 2 pairs of lungs had a high dead space fraction ( $43 \%$ and $44 \%$ ). In the remaining 4 pairs of lungs (nos. $3-6$ ), the target flow of $70 \mathrm{~mL} / \mathrm{min}$ per kilogram donor weight was reached. These 4 pairs of lungs had a considerable lower mean dead space fraction of $30 \%$. PVR were stable during the reconditioning and evaluation phases, even beyond 4 hours of perfusion (Figure 4). Hematocrit increased during EVLP from a mean of 11.8 to 12.8 $(P=.03)$, and blood glucose decreased from a mean of $12 \mathrm{mmol} / \mathrm{L}$ to $9.3 \mathrm{mmol} / \mathrm{L}(P=.03)$.

\section{Early Clinical Results}

All LTx were performed without the use of extracorporeal circulation. There was no 30-day or hospital mortality and all patients were discharged from hospital after a mean stay of 31 days (range, 25-44 days). Early lung function test prior to discharge showed that the patients, on average, had $70 \%$ of anticipated forced expiratory volume at 1 second (FEV 1.0). Data are presented in Table 6.

\section{DISCUSSION}

Our results indicate that lungs initially rejected for donation because of impaired function can be recovered during EVLP and eventually transplanted without compromising early clinical results. Six patients underwent successful LTx with initially rejected donor lungs. In 5 donors, blood gases were impaired to the extent that the lungs were deemed unusable. In 1 donor, bilateral infiltrates disqualified the lungs for transplantation, although the $\mathrm{P} / \mathrm{F}$ ratio was $>40 \mathrm{kPa}$. All donors had varying extent of pathologic findings on chest radiography. In our program, none of the lungs would normally have been used for transplantation prior to the introduction of EVLP.

Two different EVLP protocols for human lungs have been applied for clinical use. The Toronto group has developed an EVLP technique with low PA flow (40\% of estimated cardiac output), low PA pressure (10-15 mm Hg), and acellular Steen solution. ${ }^{5}$ We have adopted the EVLP protocol initially described by Steen and colleagues ${ }^{6}$ that allows higher PA flow and pressures. Perfusion is performed with Steen solution mixed with banked blood to a hematocrit of $10 \%-15 \%$. In an animal study of lungs from nonheart-beating donors with warm ischemic times of more than 1 hour, it was shown that PVR increased 


\begin{tabular}{|c|c|c|c|c|}
\hline Procedure & $\begin{array}{l}\text { De-air / Close shunt / } \\
\text { start warming / start } \\
\text { ventilation at } 32{ }^{\circ} \mathrm{C}\end{array}$ & $\begin{array}{l}\text { Evaluate / Oxygenator } \\
\text { provides no oxygenating }\end{array}$ & $\begin{array}{l}\text { Cooling } \\
\text { Stop ventilation at } 32{ }^{\circ} \mathrm{C}\end{array}$ & $\begin{array}{l}\text { Stop PA flow at } 12^{\circ} \mathrm{C} \\
\text { Institute surface cooling }\end{array}$ \\
\hline $\begin{array}{l}\text { Maximal PA } \\
\text { Flow }\end{array}$ & $\begin{array}{l}\text { Start at } 2 \text { litres }>>70 \mathrm{ml} / \\
\mathrm{kg} / \text { donor weight }\end{array}$ & $70 \mathrm{ml} / \mathrm{kg} /$ donor weight & $70 \mathrm{ml} / \mathrm{kg} /$ donor weight & 2.5 litres \\
\hline $\begin{array}{l}\text { Maximal PA } \\
\text { pressure }\end{array}$ & $15 \mathrm{mmHg}>>20 \mathrm{mmHg}$ & $20 \mathrm{mmHg}$ & $20 \mathrm{mmHg}$ & \\
\hline Ventilation & $\begin{array}{l}1,5 \times \text { flow (max } 100 \mathrm{ml} / \\
\mathrm{kg} / \text { donor) }\end{array}$ & $\begin{array}{l}1,5 \times \text { flow }(\max 100 \mathrm{ml} / \\
\mathrm{kg} / \text { donor) }\end{array}$ & $\begin{array}{l}1,5 \times \text { flow (max } 100 \mathrm{ml} / \\
\mathrm{kg} / \text { donor) }\end{array}$ & No ventilation \\
\hline $\mathrm{FiO2}$ & 0.5 & $0.5>0.21>1.0$ & 0.5 & - \\
\hline Temp & Warm to $36^{\circ} \mathrm{C}$ & $36{ }^{\circ} \mathrm{C}$ & Cool to $12{ }^{\circ} \mathrm{C}$ & $8^{\circ} \mathrm{C}$ \\
\hline
\end{tabular}

FIGURE 3. The practical, circulatory, and ventilatory settings of the different phases during ex vivo lung perfusion. $\mathrm{FiO}_{2}$, Fraction of inspired oxygen.

over time when evaluated in an EVLP model with red blood cells in the perfusate. ${ }^{9}$ Based on that study, it has been questioned whether perfusion with red blood cells can be performed safely for longer than 2 hours, ${ }^{10}$ which is sometimes needed for proper ex vivo reconditioning. However, in our series, lungs underwent EVLP for up to 5 hours with no marked increase of PVR over time, with the exception of temporary elevations seen in conjunction with lung recruitment maneuvers. During the end of EVLP, when the cooling phase is instituted, and the lung becomes cold and less compliant, PVR tends to increase (Figure 3). Cypel and associates $^{11}$ suggested that low flow is essential for successful EVLP. This might hold true when extended perfusions are anticipated, for example, in experimental organ treatment purposes. In our opinion, however, the evaluation of the lung function ex vivo should always be performed using as normal physiologic conditions as possible with respect to PA flow and pressure, blood corpuscle-containing perfusate, as well as ventilatory settings. Functional testing at low flow and low PA pressure during EVLP is not congruent with the environment in which the lung should later function.

The duration of EVLP was, in the current study, in the range of 157 to 393 minutes. A range of 53 to 98 minutes of this time was used for cooling. The seemingly large time differences are a consequence of the time needed to reach acceptable lung performance. In concurrence, with Aigner and coworkers, ${ }^{8}$ we believe that no further time needs to be spent on EVLP if blood gas values and circulatory and ventilatory data are satisfactory. On the other hand, if the initial physiologic variables are suboptimal, the reconditioning phase should be prolonged to provide time for the oncotic effect of the hyperoncotic perfusate to reduce lung water. All lungs reconditioned during EVLP increased their oxygenation capacity compared with donor blood gas recordings at time of acceptance. In this series, we believe that the most important reason for improvement of lung function is recruitment of atelectasis together with extensive clearance of bronchial secretion.

TABLE 3. Ex vivo lung perfusion duration data

\begin{tabular}{|c|c|c|c|c|c|c|c|}
\hline \multirow[b]{2}{*}{ Variables } & \multicolumn{7}{|c|}{ EVLP duration data } \\
\hline & 1 & 2 & 3 & 4 & 5 & 6 & Mean \\
\hline From start to $32^{\circ} \mathrm{C}$, min & 30 & 40 & 27 & 27 & 23 & 23 & 28 \\
\hline From start to $36^{\circ} \mathrm{C}$, min & 44 & 79 & 50 & 37 & 43 & 60 & 52 \\
\hline Reconditioning & 61 & 162 & 58 & 55 & 50 & $242^{*}$ & 104 \\
\hline Evaluation & 61 & 32 & 58 & 42 & 62 & 53 & 51 \\
\hline Core cooling & 59 & 85 & 53 & 60 & 62 & 98 & 70 \\
\hline Total EVLP, min & 193 & 305 & 169 & 157 & 174 & 393 & 231 \\
\hline Cooling method, after EVLP & Ice & Ice & SC & $\mathrm{SC}$ & SC & SC & - \\
\hline Duration, post-EVLP cooling, lung 1 , min & 299 & 285 & 328 & 303 & 237 & 260 & 285 \\
\hline Duration, post-EVLP cooling, lung 2, min & 438 & N/A & 537 & 480 & 455 & N/A & 478 \\
\hline Total time lung 1 , harvest to recipient perfusion, min & 643 & 807 & 713 & 701 & 632 & 1049 & 758 \\
\hline Total time lung 2 , harvest to recipient perfusion, min & 782 & N/A & 923 & 878 & 850 & N/A & 858 \\
\hline
\end{tabular}

$E V L P$, Ex vivo lung perfusion; $S C$, surface cooling; $N / A$, not applicable. *A first evaluation was done after 68 minutes. As a result of suboptimal partial pressure of arterial oxygen in the right lung, the phase was shifted back to reconditioning. After a total EVLP time of 242 minutes, another evaluation was performed for which data are presented. 
TABLE 4. Ex vivo lung perfusion hemodynamic and respiratory data

\begin{tabular}{|c|c|c|c|c|c|c|c|}
\hline \multirow[b]{2}{*}{ Variables } & \multicolumn{7}{|c|}{ EVLP no. } \\
\hline & 1 & 2 & 3 & 4 & 5 & 6 & Mean \\
\hline $\mathrm{P} / \mathrm{F}$ ratio, 0.5 & 29.8 & 15.8 & 29.3 & 37.7 & 22 & $25.7 \mathrm{~L}, 7.7 \mathrm{R}$ & 26.7 \\
\hline $\mathrm{P} / \mathrm{F}$ ratio, 0.21 & 11.4 & MD & 14.9 & 18 & 9.7 & $9.9 \mathrm{~L}, 5.9 \mathrm{R}$ & 12.8 \\
\hline $\mathrm{P} / \mathrm{F}$ ratio, 1.0 & 67.4 & 40.6 & 56.8 & 70.2 & 49.9 & $59.6 \mathrm{~L}, 13.6 \mathrm{R}$ & 57.4 \\
\hline Ventilation, $\mathrm{L} / \mathrm{min}$, at $\mathrm{FiO}_{2} 1.0$ & 4.3 & 4.7 & 6 & 6 & 6 & 3.8 & 5.1 \\
\hline PawP, $\mathrm{mm} \mathrm{Hg}$, at $\mathrm{FiO}_{2} 1.0$ & 12 & 15 & 17 & 16 & 15 & 13 & 15 \\
\hline Compliance at $\mathrm{FiO}_{2} 1.0$ & 56 & 53 & 65 & 64 & 63 & 53 & 59 \\
\hline $\mathrm{DSF}, \%$, at $\mathrm{FiO}_{2} 1.0$ & 44 & 43 & 45 & 17 & 32 & 28 & 35 \\
\hline $\mathrm{PaO}_{2}$ improvement from donor to $\mathrm{EVLP} \mathrm{FiO}{ }_{2} 1.0$ (best lung) & 50.7 & 23.6 & 27.1 & 28.4 & 21.0 & 50.5 & 33.6 \\
\hline PA flow, $\mathrm{L} / \mathrm{min}$, at $\mathrm{FiO}_{2} 1.0$ & 4.3 & 2.4 & 4 & 4.2 & 6 & 3.9 & 4.1 \\
\hline PA maximum flow, $\%$ of predicted, at $\mathrm{FiO}_{2} 1.0$ & 77 & 55 & 100 & 100 & 100 & 100 & \\
\hline $\mathrm{PA}$ pressure, $\mathrm{mm} \mathrm{Hg}$, at $\mathrm{FiO}_{2} 1.0$ & 19 & 20 & 15 & 19 & 18 & 16 & 18 \\
\hline PVR, dynes $\cdot \mathrm{s} \cdot \mathrm{cm}^{-5}$, at $\mathrm{FiO}_{2} 1.0$ & 576 & 682 & 308 & 371 & 240 & 330 & 418 \\
\hline
\end{tabular}

$E V L P$, Ex vivo lung perfusion; $P / F$, ratio of partial pressure of arterial oxygen/fraction of inspired oxygen; $L$, left lung; $R$, right lung; $M D$, missing data; $P a w P$, peak airway pressure; $D S F$, dead space fraction; $P V R$, pulmonary vascular resistance.

Glucose levels decreased and lactate levels increased during EVLP, as reported by others. ${ }^{12,13}$ We do not believe these are signs of impaired lung function. On the contrary, we find them congruent with normal lung metabolism as described previously. ${ }^{14}$ The pairs of lungs (nos. 2 and 6) with the poorest function were subjected to a longer EVLP time, and consequently developed lower glucose and higher lactate levels than the others.

In theory, one of the main objectives of EVLP is to mobilize extensive interstitial and/or alveolar fluid to the hyperoncotic perfusate. However, because 3 of 6 lungs gained weight during EVLP, we are not convinced that this is the main reason for improvement of the lung function. On the other hand, in lungs heavy with fluid prior to EVLP, as in 2 pairs of our lungs (nos. 2 and 6; weight, $>1500 \mathrm{~g}$ ), fluid shift from the lung to the perfusate seems a likely explanation for some of the improved lung function. One of these pairs of lungs (no. 2) was by far the heaviest and had the worst oxygenation capacity of all donor lungs. Although improvement was seen during EVLP, the

TABLE 5. Ex vivo lung perfusion laboratory data

\begin{tabular}{|c|c|c|c|c|c|c|c|}
\hline \multirow[b]{2}{*}{ Variable } & \multicolumn{7}{|c|}{ EVLP no. } \\
\hline & 1 & 2 & 3 & 4 & 5 & 6 & Mean \\
\hline Het start, \% & 12.3 & 10.9 & 11.1 & 10.7 & 12.4 & 13.3 & 11.8 \\
\hline Het final, $\%$ & 12.9 & 11.7 & 11.6 & 11.4 & 13.2 & 16 & 12.8 \\
\hline$\Delta \mathrm{Hct}, \%$ & 0.6 & 0.8 & 0.5 & 0.7 & 0.8 & 2.7 & 1.0 \\
\hline $\begin{array}{l}\text { B-glucose start, } \\
\mathrm{mmol} / \mathrm{L}\end{array}$ & 11.3 & 10.1 & 12.6 & 12.5 & 13.6 & 11.8 & 12.0 \\
\hline $\begin{array}{l}\text { B-glucose final, } \\
\mathrm{mmol} / \mathrm{L}\end{array}$ & 10.0 & 4.3 & 11.7 & 9.8 & 10.7 & $<0.1$ & 7.8 \\
\hline Weight start, g & MD & 2550 & 600 & 500 & 750 & 1650 & 1210 \\
\hline Weight final, $g$ & MD & 1950 & 1050 & 1000 & 1000 & 1250 & 1250 \\
\hline$\Delta$ Weight, $\mathrm{g}$ & MD & -650 & 450 & 500 & 250 & -400 & 10 \\
\hline
\end{tabular}

oxygenation capacity just reached the preset requirements for transplantation. The recipient operation was complicated and, therefore, lungs with very extensive edema and oxygenation capacity just reaching $40 \mathrm{kPa}$ after EVLP should be considered carefully before transplantation. A lesson learned from this suboptimal outcome, with postoperative morbidity as well as a less-than-ideal postoperative lung function, is that either transplantation should not have been performed in this patient or both donor lungs should have been implanted with postoperative extracorporeal membrane oxygenation. All other patients had an acceptable outcome with no mortality, low morbidity, and good lung function at discharge from hospital.

The yield of transplantation after EVLP was $100 \%$ in this series, which is higher than that reported by others. ${ }^{4,5,8}$ Two single lungs, however, were deemed unsuitable for transplantation in our series. We continue to evaluate selected, rejected donor lungs with EVLP.

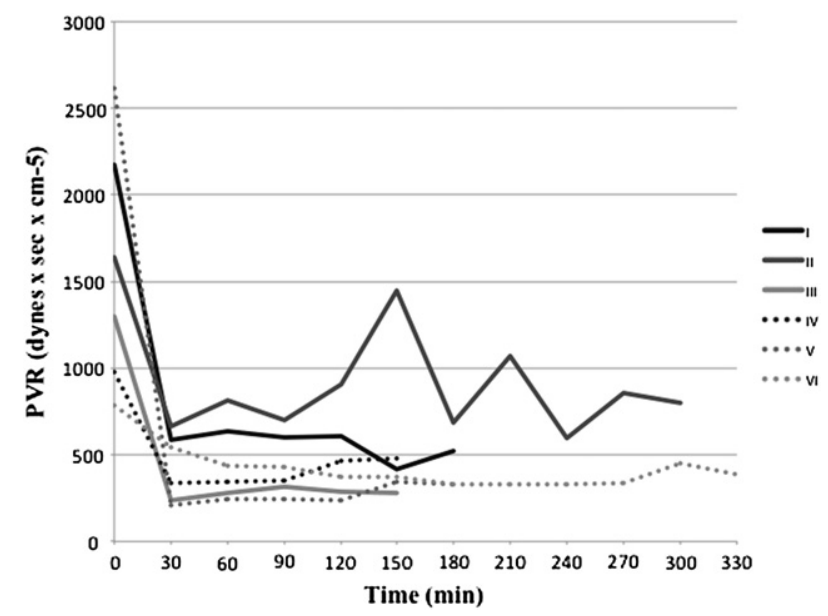

FIGURE 4. PVR over time in 6 lungs during ex vivo lung perfusion. $P V R$, Pulmonary vascular resistance. 
TABLE 6. Patient outcome after ex vivo lung perfusion and lung transplantation

\begin{tabular}{|c|c|c|c|c|c|c|}
\hline \multirow[b]{2}{*}{ Variable } & \multicolumn{6}{|c|}{ Recipient no. } \\
\hline & 1 & 2 & 3 & 4 & 5 & 6 \\
\hline Procedure & DL & SL & DL & DL & DL & SL \\
\hline $\mathrm{ECC}, \mathrm{Y} / \mathrm{N}$ & $\mathrm{N}$ & $\mathrm{N}$ & $\mathrm{N}$ & $\mathrm{N}$ & $\mathrm{N}$ & $\mathrm{N}$ \\
\hline Time to extubation, $\mathrm{h}$ & 3 & 574 & 6 & 7 & 5 & 7 \\
\hline ICU stay, $\mathrm{h}$ & 40 & 625 & 73 & 54 & 152 & 40 \\
\hline PGD grade at 72 hours* & 0 & 2 & 0 & 1 & 1 & 0 \\
\hline Hospital stay, d & 27 & 44 & 39 & 27 & 25 & 25 \\
\hline \multicolumn{7}{|l|}{ Spirometry at discharge } \\
\hline FEV 1.0, \% expected & $1.7 \mathrm{~L}, 75 \%$ & $1.1 \mathrm{~L}, 40 \%$ & $2.2 \mathrm{~L}, 64 \%$ & $2.1 \mathrm{~L}, 76 \%$ & $3.2 \mathrm{~L}, 88 \%$ & $1.7 \mathrm{~L}, 74 \%$ \\
\hline FVC, \% expected & $2.2 \mathrm{~L}, 82 \%$ & $1.8 \mathrm{~L}, 56 \%$ & $3.0 \mathrm{~L}, 76 \%$ & $2.2 \mathrm{~L}, 69 \%$ & $3.8 \mathrm{~L}, 83 \%$ & $1.8 \mathrm{~L}, 66 \%$ \\
\hline
\end{tabular}

$D L$, Double lung; $S L$, single lung; $E C C$, extracorporeal circulation; $Y$, yes; $N$, no; $I C U$, intensive care unit; $P G D$, primary graft dysfunction; $F E V$, force expiratory volume; $F V C$, force vital capacity. *PGD was defined as grade $0, \mathrm{PaO}_{2} / \mathrm{FiO}_{2} \geq 40 \mathrm{kPa}$ with a clear chest radiograph; grade $1, \mathrm{PaO}_{2} \geq 40 \mathrm{kPa}$ with infiltration on chest radiographs; grade 2 , $\mathrm{PaO}_{2} / \mathrm{FiO}_{2} \geq 27$ but $<40 \mathrm{kPa}$; and grade $3, \mathrm{PaO}_{2} / \mathrm{FiO}_{2}<27 \mathrm{kPa}$.

\section{Limitations}

We believe that this EVLP concept is safe, and that proofof-concept has been shown by others. In our experience, the Vivoline system has been reliable; however, this case series is small and has no control group. Moreover, the included lungs are heterogeneous and therefore conclusions have to be drawn very cautiously.

\section{CONCLUSIONS}

In conclusion, the use of EVLP seems safe and indicates that lungs otherwise refused for LTx can be recovered and used subsequently for transplantation with acceptable results. However, the system comes with a considerable cost. Larger series of patients as well as long-term data are required before EVLP can be determined as an important adjunct to LTx.

We thank all the participants of the lung transplant team at the Sahlgrenska University Hospital for dedicated clinical work.

\section{References}

1. The U.S. Organ Procurement and Transplantation Network and the Scientific Registry of Transplant Recipients 2011. Available at: http://optn.transplant. hrsa.gov/latestData/rptData.asp.

2. NHS Blood and Transplant. Transplant activity in the UK. Activity report 2010/2011. Available at: http://www.organdonation.nhs.uk/ukt/statistics/ transplant_activity_report/current_activity_reports/ukt/activity_report_2010_ 11.pdf.
3. Ingemansson R, Eyjolfsson A, Mared L, Pierre L, Algotsson L, Ekmehag B, et al. Clinical transplantation of initially rejected donor lungs after reconditioning ex vivo. Ann Thorac Surg. 2009;87:255-60.

4. Zych B, Popov AF, Stavri G, Bashford A, Bahrami T, Amrani M, et al. Early outcomes of bilateral sequential single lung transplantation after ex-vivo lung evaluation and reconditioning. J Heart Lung Transplant. 2012;31:274-81.

5. Cypel M, Yeung JC, Liu M, Anraku M, Chen F, Karolak W, et al. Normothermic ex vivo lung perfusion in clinical lung transplantation. N Engl J Med. 2011;364: 1431-40.

6. Steen S, Ingemansson R, Eriksson L, Pierre L, Algotsson L, Wierup P, et al. First human transplantation of a nonacceptable donor lung after reconditioning exvivo. Ann Thorac Surg. 2007;83:2191-4.

7. Lindstedt S, Hlebowicz J, Koul B, Wierup P, Sjogren J, Gustafsson R, et al. Comparative outcome of double lung transplantation using conventional donor lungs and non-acceptable donor lungs reconditioned ex vivo. Interact Cardiovasc Thorac Surg. 2011;12:162-5.

8. Aigner C, Slama A, Hotzenecker K, Scheed A, Urbanek B, Schmid W, et al. Clinical ex vivo lung perfusion: pushing the limits. Am J Transplant. 2012;12: 1839-47.

9. Erasmus ME, Fernhout MH, Elstrodt JM, Rakhorst G. Normothermic ex vivo lung perfusion of non-heart-beating donor lungs in pigs: from pretransplant function analysis towards a 6-h machine preservation. Transplant Int. 2006;19:589-93.

10. Cypel M, Keshavjee S. Extracorporeal lung perfusion. Curr Opin Organ Transplant. 2011;16:469-75.

11. Cypel M, Yeung JC, Hirayama S, Rubacha M, Fischer S, Anraku M, et al. Technique for prolonged normothermic ex vivo lung perfusion. J Heart Lung Transplant. 2008;27:1319-25.

12. Koike T, Yeung JC, Cypel M, Rubacha M, Matsuda Y, Sato M, et al. Kinetics of lactate metabolism during acellular normothermic ex vivo lung perfusion. J Heart Lung Transplant. 2011;30:1312-9.

13. Valenza F, Rosso L, Pizzocri M, Salice V, Umbrello M, Conte G, et al. The consumption of glucose during ex vivo lung perfusion correlates with lung edema. Transplant Proc. 2011;43:993-6.

14. Fisher AB. Intermediary metabolism of the lung. Environ Health Perspect. 1984; 55:149-58. 